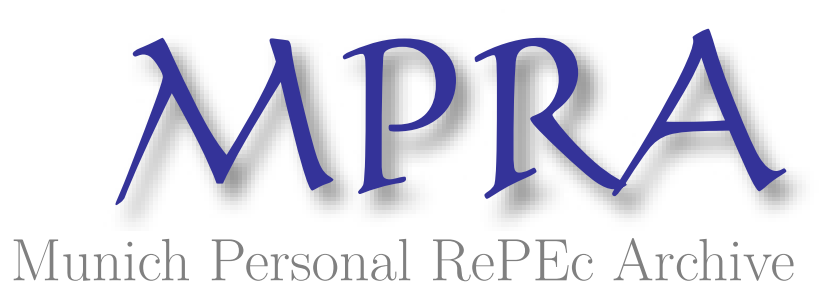

\title{
On the mathematical foundations of political economy
}

Chichilnisky, Graciela

1990

Online at https://mpra.ub.uni-muenchen.de/8123/

MPRA Paper No. 8123, posted 07 Apr 2008 04:39 UTC 


\title{
ON THE MATHEMATICAL FOUNDATIONS OF POLITICAL ECONOMY*
}

\author{
GRACIELA CHICHILNISKY \\ Columbia University
}

Political economy views economic issues through the lens of political organisation. In today's world, it must focus on the roles of markets and of democracy, two concepts which are driving revolutionary changes in the political organisation of both Europe and Asia. There are two main paradigms for the analysis of markets and democracy, both of which have been mathematically advanced over a number of years: the general equilibrium theory of markets, and social choice theory, which examines practical aspects of democracy. ${ }^{1}$ While it is true that political economy has made some limited use of the latter in order to examine political-economic issues of democracy, it has made little use of the former, the theory of market behaviour.

The general equilibrium theory of markets has become a solid and intellectually appealing thinking edifice. Its foundations have achieved the formidable status of common knowledge. The first two Welfare Theorems link perfect market equilibria with efficiency in the allocation of resources, and with the individual's egoistic utility maximising goals. ${ }^{2}$ These theorems have been perfected over a number of years in several directions. ${ }^{3}$ Other results exist in the theory of international markets which link market efficiency with the international division of labour and with 'gains from trade'. ${ }^{4}$ These have also achieved the status of common knowledge, and their influence on policy is pervasive. However, the lack of major intellectual advances in the theory of international markets in the last forty years, seems to anticipate its demise; for common knowledge follows theoretical advances, or the lack of them, with a lag.

\footnotetext{
*This paper was prepared for the Political Economy Lecture, Harvard University, 22 March 1990. I thank the audience, particularly Juliet Schor and Amartya Sen, and Murray Milgate for valuable comments.

'Arrow and Hahn (1971), and Sen (1970) provide main references.

${ }^{2}$ Debreu (1954) offers a general presentation.

${ }^{3}$ A survey of results in this literature is in Arrow and Hahn (1971).

'A mathematical exposition of the classical Heckscher-Ohlin model is in Jones (1965).
} 
The major advances in the general equilibrium analysis of markets, of course, were not achieved by political economists. They were achieved by economic theorists without any explicit concern for the current issues of political economy. This is partly due to the literary rather than mathematical approach to political economy which has been generally adopted during the last half century. By a mathematical approach I do not mean the application of statistical techniques to analyse data, nor the application of lesser mathematical theorems or techniques. A mathematical approach involves the sharp and illuminating effect of abstract, general and qualitative thinking, a process through which new mathematics is created. The fear that mathematical analysis places the subject into the straight-jacket of quantitative thinking is unfounded: qualitative mathematics such as topology or logic have produced valuable insights into the functioning of economic systems, particularly in social choice theory and in the theory of markets.

Mathematics provide a clear logical basis for analysis, and also a means to advance the logical analysis into practical and empirically testable propositions and policies. A clear internal logic is fundamental for the dissemination of the arguments. It is also fundamental for the participation in the debate of those whose lives are affected by the evolution of ideas.

Changes in economic and political organisations are driven by such ideas. The strong mathematical developments in the theory of markets of the last forty years are not incidental to the driving power it achieved. Without strong, clear and commonly accepted foundations, intellectual developments cannot take place. Intellectual work without such foundations builds on moving sands. It must start again with each paper, each book, each concept. It is an exhausting and often futile enterprise. The whole structure of the edifice weakens and finally collapses.

\section{AN AGENDA FOR POLITICAL ECONOMY}

Today's global embrace of markets and democracy will stretch the resources of existing theories. It seems clear that in Eastern Europe markets are desired as representatives of freedom, as doors to escape totalitarian control and its hardships, and to liberate economic resources to productive activities. Democracy provides a hope for participation in the political organisation. In view of the prominence achieved by these concepts, and the hopes placed on them, theoretical advances in the theories of markets and democracy are needed more than ever. Several areas seem ripe for analysis, but only three will be discussed here: markets and democracy, the perfect market and its environment, and policies and market responses. These three areas are chosen because of their importance and their proven fertility in producing interesting insights which have attracted wide attention.

'Topological foundations of social choice theory were established in Chichilnisky (1980A). Global analysis of competitive markets in, for example, Debreu (1976) and Chichilnisky (1986B).

\section{Markets and Democracy}

The connection between democracy and markets is not at all clearly understood. Free markets are one form of economic activity which emerges in free societies. Both have occurred in less free societies, indeed democracy emerges in the context of strongly repressed minorities (for example, slavery) and free markets have coexisted with repressive and totalitarian regimes, as is generally accepted in the case of Chile until very recently. The connection between these two concepts has indeed been discussed by literary means; but it has not been logically or mathematically analysed in the context of a well-defined model. This is the foundation which is needed.Since both the theory of markets and the theory of social choice have been mathematically formalised (see Arrow and Hahn, 1971; Sen, 1970; Chichilnisky, 1980A), this should not be an impossible task. We need clear, general results about this important issue. We need a mathematical approach, to determine positive findings, the boundaries of what is known or agreed, and the empirical conditions under which different relationships occur. We need a logical foundation and a mathematical edifice to build upon these areas which are the daily concern of many people across the world.

The agenda and the methodology of research on markets should be taken up by political economists. It should not be left to other areas. The problem of market imperfections, which has occupied much of the literature in economic theory over the last decade, is of lesser import, since any result in this area is suspect of disappearing once the markets are perfected. Perfect markets should be examined by political economists, and using state of the art methodologies. As part of this agenda, the theory of markets in its general and elegant form must be extended to more realistic economic environments. This means that without changing the 'perfectly competitive' market structure, certain meta-assumptions which are always automatically accepted as the market's 'environment', but which are artificial, should be improved. Doing do could bring powerful and general results which will be useful in developing realistic aspects of the theory.

\section{Competitive markets with endogenous endowments}

The most widely accepted formalisation of a competitive market economy is the Arrow-Debreu model (see, for example, Arrow and Hahn, 1971). In this model, the initial endowments of the economy are not explained by the market conditions, but rather are exogenous parameters that describe the non-market environment. In all versions of that model, the initial endowments are described by a fixed vector in Euclidean space, a vector which is given to the market as an initial condition, and which is not related to the market behaviour in any way. The fixed endowments in the Arrow-Debreu model are therefore a feature of the model which is unrelated to the competitive market behaviour. The existence of such unexplained objects is not a unique feature of the competitive market model. Indeed, all mathematical models are defined by providing 'primary' objects, which are taken as given and not 
explained by the model. These are typically the rules of the logic utilised by the model, the language, and the axioms of the model. Such is the role of the initial endowments in the model that is accepted widely as the paradigm of competitive markets.

In the competitive market model, endowments are not unique in this treatment: technologies (production functions) and individual preferences (or utility functions) are also treated as 'primitive', and are therefore left unexplained by the model. Technologies, utilities and endowments are given initially and are assumed not to depend on market behaviour. They are part of the model's external environment. Thus changing the assumption on how the endowments are given, or changing the way technologies and preferences are given, changes the way in which the environment of the competitive market is defined. These changes are suggested here as a way of improving the model, and of enriching its results.

It is rather natural that initial endowments may vary in a manner which depends on the market behaviour. A case in point is given by resources. The literature on resource economics has considered initial endowments of resources as price dependent. They depend on prices in two ways: in one, the initial endowment of a resource is measured with respect to the economically feasible quality or 'grade' of the resource, namely that quality which yields a greater energy value than it costs to extract or produce. As prices change the quantity of the resource available changes: more initial endowments (i.e. endowments of lower grade) become economically feasible at higher energy prices. Tar sands, a form of oil resource, became economically feasible as the price of oil escalated quickly in the 1970 s, and the total quantity of that oil resource was therefore expanded to include tar sands. Another way in which initial endowments of resources vary as function of prices is through the production of the resources. The research, discovery and extraction of a resource are economic activities closely related to prices. As market prices of the resource increase, more research and development takes place, and more of the endowments is uncovered. There are, in all, more initial endowments of the resource for the economy (see, e.g. Heal, 1980).

Other areas of economics have also investigated the issue of variable or marketdependent initial endowments. In international economics, Kemp and Jones (1972), Chichilnisky (1981, 1986A), and Findlay and Kierkowski (1983) among others have investigated fruitfully the implications of a variable labour supply in general equilibrium models of international trade. These are models which share many of the Hekscher-Ohlin characteristics but rather than assuming that initial endowments (of capital or labour) are fixed, these are allowed to vary with market prices.

There is another manner in which the variation of initial endowments has been considered: in the case of transfers. Here total initial endowments of the economy remain fixed, but the quantity of these endowments allocated to the different agents changes. One considers changes of the initial endowments of two parties: the donor and the receiver. The total quantity of the endowment in the economy remains fixed, since the amounts donated and received cancel out. There is however a methodological difference between transfers and endogenous endowments. Here initial endowments of the agents do not vary with market conditions. Rather, they are changed by a voluntary act which is outside the market functioning, such as a gift or transfer. The issue is the impact that such changes have on the solutions, i.e. the comparison of the equilibria of the model before and after the transfer. In other words, one studies the effects on the equilibrium market prices of shifting the allocation of initial endowments among the agents in the economy.

The study of such shifts and the corresponding market prices in the new equilibrium is properly described as 'comparative statics'. Traditionally transfer problems were studied in international economics in the context of $2 \times 2 \times 2$ models of international trade (two goods, two countries, two inputs of production). Significantly more flexibility was added in Chichilnisky (1980B) with the inclusion of one more country, resulting in a $2 \times 3 \times 2$ model of trade, again an instance of the ArrowDebreu model of competitive markets. This time the total initial endowments are fixed, and one studies the comparative statics of transfers, i.e. changes in the market equilibrium which occur as the allocations among the parties is varied by a transfer or gift from one country to another. This added flexibility in the model's environment resulted in novel and widely debated results, in particular in the discovery that transfer paradoxes do occur in standard situations such as in stable markets with unique equilibria, a phenomenon which was considered impossible before Chichilnisky (1980). The so called transfer paradox is the fact that after a gift, the donor is better off and the receiver worse off, in the new equilibrium. This is due to the new market prices, also called terms of trade, which favour the donor and disfavour the receiver. Further results refined the initial theorems, providing e.g. necessary and sufficient conditions for this transfer paradox to occur (Chichilnisky, 1983). A lively debate and a large literature emerged from the discovery of the transfer paradox in stable markets with three or more countries (see e.g. Geanakoplos and Heal, 1983).

It is worth emphasising that none of these authors nor their models challenge the perfectly competitive assumptions of the market. They all assume perfectly competitive markets. The only difference is in their formalisation of one of the aspects of the perfect market's environment. In some, this refers to the initial endowments. These are no longer exogenously given parameters, but they are rather explained by the market behaviour. Initial endowments are therefore endogenous to the model. In the other cases, initial endowments are fixed but one studies the impact of reallocating them among the agents of the model. The number of agents is increased from two, the traditional number of countries in international economics, to three.

The procedure of endogenising endowments should be differentiated from the practice of altering the standard competitive market assumptions, of introducing market imperfections. The latter is arguably a less preferable practice, because such imperfections are often seen as approximations to the competitive model, and thus less robust. The results often 'wash away' as new markets are introduced to deal 
with the imperfection in the old ones. Models with imperfections have therefore less theoretical appeal and strength. Although in the short run they appease our need for more realism, in practice, models of market imperfections have simply reinforced the unique position of the perfectly competitive market model in the theory of markets. The perfectly competitive model as formalised by Arrow and Debreu or related versions (a special case of which is the typical $2 \times 2 \times 2$ model of international trade) remains the conceptual yardstick with which we measure new results. It remains the more general, clear, solid conceptualisation of markets. It remains the theoretical standard of the theory.

The endogenisation of initial endowments has significant practical implications. While not changing the conceptual market structure of the perfectly competitive model, when endowments are endogenous, depending for instance on market prices, the results of the theory are significantly altered. They appear to be more realistic and appealing, as will be discussed below. Before presenting some examples, it may be useful to point out that I do not refer here to price-dependent resources which appear because the resources are treated as produced goods rather than as initial data. For example, one could consider oil a produced good and its quantity would be explained by the behaviour of competitive producers who maximise profits. This is a legitimate exercise, and it yields a price-dependent supply of oil. In this sense, it may be said that in such a model oil endowments are endogenous. However, if the producers face some other exogenously given fixed endowment, for example, land, to produce oil, the procedure is simply another version of the Arrow-Debreu exogenous endowment in disguise. As long as the economy's producers face a fixed and non-market dependent initial endowment, we are back in the Arrow-Debreu formulation. The results of the theory are therefore, as can be expected, the same as those of the Arrow-Debreu model.

The differences arise when exogenous fixed initial endowments for a particular produced good do not exist at all, that is, when for a good that is used as an input of production, the initial endowments are not explained as being produced by profit maximisers from some other fixed quantity of goods which is in turn, left unexplained. There must be some input which is genuinely endogenous in the sense that its initial endowments are not exogenously fixed, nor explained as produced from other exogenously fixed endowments. When at least some of the goods have this latter property, then the model is said to have endogenous endowments, and the results of the theory are significantly altered. The next section explores these differences.

In one case, the Pareto optimality of the competitive equilibrium is lost so that pricing policies can improve overall welfare. This happens because the overall production set (as endowments vary) is non-convex, even though the technologies are all convex. Endogenous endowments are also shown to lead to substantial differences in the properties of general equilibrium models of international trade, and we shall also see examples of this type. Finally, we refer to the variation of initial endowments of the agents in the case of transfers, and discuss the results obtained by the expansion of the traditional two-country environment to three countries. 2(a) Endogenous endowments: non-convexities with constant returns to scale

We consider an economy with market responsive endowments ${ }^{\prime}$ and constant returns to scale technologies. We demonstrate that the model has a unique stable competitive equilibrium which is Pareto inefficient. This property is robust in the sense that it is maintained for variations of every parameter in the model within an interval of positive measure. We show that, owing to the endogeneity of the endow ments, the overall production frontier of this model is non-convex, even though for each fixed endowment, the production functions display constant returns to scale The non-convexity is produced by the response to prices of the initial endowments, and leads to losses of market efficiency. Except for having endogenous initia endowments, the model is an instance of the Arrow-Debreu model of a perfectly competitive market economy.

There are two outputs which are denoted $B$ and $I$ (in sympathy with the notation of Chichilnisky, 1986). There are two inputs, $R$ (for resources) and $M$ (for machines), the endowments of which are both price dependent. The technology is described by

$$
\begin{gathered}
B=\min \left(R^{B} / \mathrm{a}_{1}, M^{B} / \mathrm{c}_{1}\right) \\
I=\min \left(R^{\prime} / \mathrm{a}_{2}, M^{I} / \mathrm{c}_{2}\right)
\end{gathered}
$$

where $R^{B}$ denotes the amount of input $R$ used in producing output $B$, etc. We let

$$
D=a_{1} c_{2}-a_{2} c_{1},
$$

the determinant of the matrix of technical coefficients.

The endowments of the two inputs are given by

$$
\begin{gathered}
R=a p_{R} / p_{B}+\bar{R} \\
M=b\left(p_{M} / p_{B}\right)^{2}+\bar{M},
\end{gathered}
$$

where $a$ and $b$ are positive numbers, $\bar{R}$ and $\bar{M}$ indicate resources available at zero prices, and $p_{x}$ denotes the price of good $x$. Endowments are thus endogenous: their supply is described by a function which is homogeneous in degree zero in prices, and non-decreasing in the relative price of the good concerned.

The technology displays constant returns to scale and fixed proportions, so that profit maximisation implies zero profits and the output prices must satisfy:

$$
\begin{aligned}
& p_{\mathrm{B}}=\mathrm{a}_{1} p_{R}+\mathrm{c}_{1} p_{M} \\
& p_{\mathrm{I}}=\mathrm{a}_{2} p_{R}+\mathrm{c}_{2} p_{M}
\end{aligned}
$$

which in turn imply:

$$
p_{R}=\left(p_{B} \mathrm{c}_{2}-p_{I} \mathrm{c}_{1}\right) / D
$$

The example presented here was developed initially in Chichilnisky and Heal (1979) and based on a model by Chichilnisky (1981, 1986A) 


$$
p_{M}=\left(p_{I} a_{1}-p_{B} a_{2}\right) / D .
$$

Similarly, input requirements are given by:

$$
\begin{aligned}
& R=B \mathrm{a}_{1}+I \mathrm{a}_{2} \\
& M=B \mathrm{c}_{1}+I \mathrm{c}_{2}
\end{aligned}
$$

which imply that when inputs are used efficiently

$$
\begin{aligned}
& B=\left(R \mathrm{c}_{2}-M \mathrm{a}_{2}\right) / D \\
& I=\left(M \mathrm{a}_{1}-R \mathrm{c}_{1}\right) / D .
\end{aligned}
$$

We complete the model by supposing there to be a single consumer who owns the entire supplies of both inputs, and uses the proceeds from the sale of these to purchase outputs. The utility function of this consumer is

$$
U(B, I)=c B+d I,
$$

with both $c$ and $d$ positive numbers. In equilibrium, if both $B$ and $I$ are produced (and we shall give conditions which ensure this subsequently),

$$
p_{B}\left|p_{I}=c\right| d \text {. }
$$

The consumer's income $Y$ is

$$
\begin{aligned}
Y & =p_{M} M+p_{R} R \\
& =p_{M} b\left(p_{M} / p_{B}\right)^{2}+p_{M} \bar{M}+p_{R} a p_{R} / p_{B}+p_{R} \bar{R}
\end{aligned}
$$

and the balancing of the consumer's budget requires that

$$
p_{I} I+p_{B} B=Y
$$

at prices satisfying (14), the consumer will be indifferent between all $(B, I)$ pairs satisfying (16). Outputs are therefore determined entirely on the supply side by (11) and (12). It is tedious but trivial to substitute these into (16), use (3), (4) and (6) and verify that at these outputs and prices the consumer's budget balances. A competitive equilibrium is therefore characterised by a set of prices at which all markets clear, and by optimising behaviour of producers and consumers. In view of the above an equilibrium is characterised by the equations:

$$
p_{B}{ }^{\star}=c, p_{I}{ }^{\star}=d, p_{R}{ }^{\star}=\left(c c_{2}-d c_{1}\right) / D
$$

and

$$
p^{\star}{ }_{M}=\left(d \mathrm{a}_{1}-c \mathrm{a}_{2}\right) / D,
$$

and the values of $R^{\star}, M^{\star}, B^{\star}$, and $I^{\star}$ which can be computed from (3), (4), (11), and (12) by substitution. Denote the associated output levels by $\left(B^{\star}, I^{\star}\right)$. It is convenient, though not essential, that these are strictly positive, so we shall establish

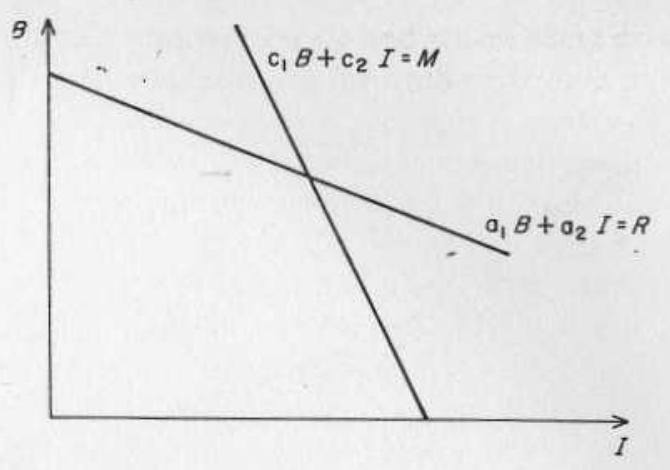

Figure 1.

conditions to ensure this. In particular, we shall establish conditions under which $\left(B^{\star}, I^{\star}\right)$ is given by the intersection of the lines representing the resource constraints

$$
\mathrm{c}_{1} B+\mathrm{c}_{2} I=M
$$

and

$$
\mathrm{a}_{1} B+\mathrm{a}_{2} I=R \text {. }
$$

Except in singular cases, which can be neglected because of the openness of the resúlts established in Chichilnisky and Heal (1979), this must occur at a strictly positive output vector, see Fig. 1.

At the intersection of the two resource constraints, both inputs are fully used and so command strictly positive prices. We are therefore interested in establishing conditions under which $p_{R}$ and $p_{M}$ are strictly positive. It is clear from this construction that the equilibrium, if it exists, will be unique.

From (17),

$$
\begin{gathered}
p_{R}>0 \text { iff }\left(c \times c_{2}\right) / D>\left(d \times c_{2}\right) / D \\
p_{M}>0 \text { iff } d a_{1} / D>c a_{2} / D .
\end{gathered}
$$

Suppose that $D>0$. Then $\mathrm{a}_{1} / \mathrm{a}_{2}>\mathrm{c}_{1} / \mathrm{c}_{2}$, and (18) implies

$$
a_{1} / a_{2}>c / d>c_{1} / c_{2}
$$

whereas if $D<0, a_{1} / a_{2}<c_{1} / c_{2}$, and (18) implies

$$
\mathrm{a}_{1} / \mathrm{a}_{2}<c / d<\mathrm{c}_{1} / \mathrm{c}_{2} \text {. }
$$

So (19) or (20), together with the corresponding sign of $D$, are sufficient to ensure that $\left(B^{\star}, I^{\star}\right)$ is positive. We have therefore shown the existence of a positive price equilibrium, under the conditions. Next is the proof of the inefficiency of this equilibrium. The proof itself is contained in the Appendix, but the argument is illustrated in Fig. 2 and discussed below. 


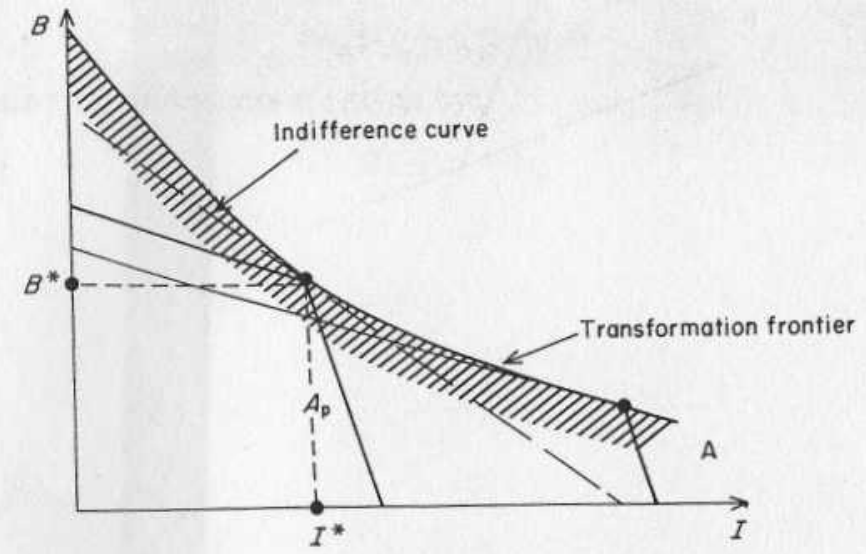

Figure 2.

In Fig. 2, $A$ denotes the production possibility set in $B$ and $I$ with the initial endowments available when the price vector is $p$, and $A$ denotes the union of the sets $A_{p}$, for all p. At $\left(B^{\star}, I^{\star}\right)$ an indifference curve, which is identical with a price line, is tangent to the feasible set defined by the intersection of $M$ and $R$ constraints. If $B^{\star}$ and $I^{\star}$ are strictly positive, and if the locus of intersection of these constraints is the graph of a convex function (this locus gives the boundary of the projection of $A$ into output space), then the linear utility function cannot assume its maximum over $A$ at $\left(B^{\star}, I^{\star}\right)$. All that remains to be shown is, as prices vary, the locus of the intersection of the two constraints traces out the graph of a convex function. A sufficient condition for this is that the derivative $\mathrm{d}^{2} B / \mathrm{d} I^{2}>0$. This is shown in the Appendix. The relevant frontier is thus always convex, and the equilibrium is always inefficient under the convexity conditions, namely higher indifference curves could be attained from the resources available at prices other than the equilibrium prices. Such inefficiencies of the competitive equilibrium cannot occur with fixed initial endowments. In this case, the competitive equilibrium is always Pareto efficient.

It is apparent that the conditions (19) and (20), used to establish the strict positivity of $B^{\star}$ and $I^{\star}$, are conditions which are satisfied by sets of the parameter values $\mathrm{a}_{1}, \mathrm{a}_{2}, \mathrm{c}_{1}, \mathrm{c}_{2}, a, b, c$ and $d$ which contain open sets. The essential property of the example is thus robust to changes in the values of the parameters specifying the technology, preferences and the endowment functions. Indeed it should be quite clear that the linearity that has been assumed for the technology and the preferences is assumed for computational convenience only and that similar non-linear relationships could give the same result.

In sum: endogeneity in the initial endowments generates certain non-convexities in production and inefficiencies in the market equilibrium even when preferences have the standard characteristics assumed in the Arrow-Debreu model, when technologies have constant returns to scale and where there exist no market imper-
fections. We showed an example where for each price, the production possibility set is convex, but it becomes non-convex as resources vary with different prices. We showed that this produces inefficiencies in the competitive equilibrium. The equilibrium is unique and the properties mentioned are robust in the sense that they remain invariant with small changes in the parameters of the model.

In Chichilnisky and Heal (1979) it is also shown that the unique equilibrium in the above example is Walrasian stable. We could say that the competitive equilibrium is 'restricted' Pareto efficient in the sense that at the equilibrium prices and the corresponding initial endowments, the equilibrium is indeed Pareto efficient. This follows from the fact that at those prices and those (fixed) endowments the model is identical to the Arrow-Debreu model of competitive markets. However, there is no reason for restricting the allocations to those available for one price only, even if this is a market clearing price. When all possible prices, and thus all potential initial endowments, are considered, the Pareto efficiency of the competitive equilibrium is lost. In view of these results, it would be natural to study the conditions on endowment responses under which the competitive equilibrium regains its efficiency, and no intervention is needed.

It should be noted that non-convexities in production do not imply that competitive equilibrium is inefficient. In Arrow-Debreu market economies with fixed initial endowments competitive equilibrium is always Pareto efficient, quite independently from the convexity of the production possibility set. In a fixed endowments economy, a competitive equilibrium set of prices always separates feasible outputs from allocations with higher indifference levels, so that we indeed have Pareto optimality of the competitive equilibrium, even with non-convexities in production.

However, in convex economies with variable endowments the situation is quite different. At the equilibrium price the production possibility frontier is convex, and at those prices and the corresponding endowments, the equilibrium allocation is indeed Pareto efficient. However, there exist other prices and the corresponding endowments at which higher indifference surfaces may be achieved, even though markets may not clear. The example provided above shows this effect clearly. Further discussion is found in Chichilnisky and Heal (1979); other references for economies with nonconvexities and providing similar arguments for the fixed endowments case, are provided in Brown and Heal $(1979,1983)$ and Chichilnisky (1990B).

\section{2(b) Endogenous endowments and relative advantages}

International economics has investigated the issue of variable endowments for several years, see e.g. Kemp and Jones (1972). In Chichilnisky (1981) a point was raised which had not been considered before: that in Arrow-Debreu markets where endowments are allowed to vary endogenously with prices, both 'gains from trade' and the (Heckscher-Ohlin) theory of relative advantages are qualified strongly, and 
$\mathrm{n}$ many cases appear to reverse. These results are obtained in models with constant eturns to scale in production. They show that a country may be worse off by xporting further quantities of the good in which it has a relative advantage, in the ense that larger quantities of exports leads to lower terms of trade, a worsening listribution of income, and lower production and consumption of both goods in the xporting country. Reciprocally, the importing country benefits unequivocally rom the new situation as it consumes more of both goods, imports more at a ower total cost, and exports less receiving more total revenues for the exports. The heorems in Chichilnisky (1981 and 1986A) provide a range of parameters for the egative effects of export led policies on the exporting country, and this leads to pecific policy recommendations about when there are gains from further trade, and when there are not. The results obtained in $2 \times 2 \times 2$ models of international trade with variable endowments are still general and elegant, but have more depth and are more relevant to today's concerns. For example, they recommend circumstances in which leapfrogging into new technologies is more appropriate than emphasising historically given relative advantages (see e.g. Chichilnisky, 1981, 1986A, 1990A). These results gave rise to an extensive literature and a lively debate about the adjustment processes towards a Walrasian equilibrium which has only recently been settled (see Lysy, 1985, Chichilnisky, 1986A).

The formulation of markets with endogenously determined (i.e. market responsive) endowments seems more realistic than that of fixed initial endowments. So does the prescription now obtained of not specialising in relative advantages in certain cases, in order not to emphasise a relative weakness. Many relative advantages are better lost than emphasised. Poor countries have a relative advantage in manual work which is poorly paid. Their best strategy may be in escaping this relative advantage as soon as possible, as done by the Asian Tigers, and specialise quickly in capital and skill intensive solutions. Women have a relative advantage at having children and caring for them, but again they may be better off escaping the specialisation in this relative advantage since it is not well rewarded. Similarly, there are limits beyond which an emphasis on international trade over and above domestic development, seems misplaced. It can lead to a break between the chain that links supply and demand. This happens where local markets are only sources of supply (cheap labour) and foreign markets source of demand. Thus the balancing effect of the two sides of the market is greatly weakened.

The general point is that the assumption of fixed endowments singles endowments out as variables which do not depend on market forces, while others do. This assumption is at the root of many important traditional results of the theory. Its removal has been and will continue to be fruitful in the research agenda of competitive markets.

The discovery of the reversal of gains from trade and relative advantage theories as soon as endowments are market dependent, has led to many studies in international economics and in general equilibrium theory. ${ }^{1}$ It promises to make the 'See, for example, the references provided in Chichilnisky (1986A). general theory of international markets more adapted to today's concerns. Whenever trade takes place between 'unequals', agents with widely different endowments and consumption patterns, as is the often case in our world economy, these considerations are likely to emerge in all their strength. It is under those conditions that endowments tend to vary with market conditions. For example, the supply of labour to a given market is not fixed but rather strongly dependent on prices, when the market stands within a larger area with much lower income per capita. Similar considerations apply to capital markets. These are the cases where gains from trade must be qualified, and where the theory of relative advantages applies only up to a point, beyond which it can be said to backfire.

\section{Variable endowments: transfers and markets}

Transfers between the parties of a competitive market are another instance of variable endowments. The overall endowments of the economy remain fixed, but variation is allowed on the initial allocation of the various agents. As these individual allocations (which remain fixed in the Arrow-Debreu model) vary, the competitive equilibrium changes and with it the welfare of the agents. An example is provided by the interaction between transfers (such as those being made by Western Europe to reallocating Eastern Europeans at present) and market prices. Transfers change the endowments of the agents. As such, they change the economic environment, and therefore the market prices at the new equilibrium. In perfect markets this can have negative effects on the receivers of the transfer, since prices can rise against them and defeat the original intention of the transfer. This is the classic transfer problem which was recently shown to occur within the framework of a perfect and stable general equilibrium economy, provided the economy has at least three agents ${ }^{1}$, a result which generated wide interest. The importance of this result resides in the general framework of competitive general equilibrium theory within which it was obtained. The attention it created is due to the intrinsic power of a mathematical approach which provides a strong basis for building, and which allows the result to stand along with the major theorems of welfare economics in the general equilibrium theory of markets.

It is of interest that what we call a transfer paradox is an effect regarded as quite standard in policy circles. Consider for example the loans of approximately DM5 bn currently made to the USSR by major German banks, with the credit backing of the West German government. It is reasonably expected that this 'transfer' (namely the government's security offered so that the loans be extended) will eventually benefit the German economy because of market responses: it will lead to increased demand for German exports to the USSR, and to better terms of

'The discovery that the transfer paradox occurs in stable markets, namely that in a stable market the donor of a transfer may benefit while the receiver loses due to new market prices is in Chichilnisky (1980B). Numerous other pieces including Chichilnisky (1983) Geanakoplos and Heal (1983), and others have subsequently enlarged the literature on the subject. 
trade for Germany. This is in effect what the transfer paradox predicts. Adding more realistic assumptions about the market environment may allow the standard theory of competitive markets to explain common sense results, without resorting to $a d$ hoc assumptions about market failures.

\section{Mixed economies: policies and market responses}

Little is known of the general equilibrium of mixed economies, which are the economies we all live in. The interaction between policies and the free market are still to be understood. Some of this has been formalised in the theory of so called rational expectations. The formalisation assumes that the agents know how to compute the impact of policies on the general equilibrium, i.e. how to compute the market response to policies, and use this knowledge in their decision making. This assumption breaks with the tradition of the competitive agent which is assumed to assumption breaks with the tradition of the competitive equilibrium. The theory of rational expectations, however, deals with a very special case, where the agents rational expectations he new equilibrium only when a certain parameter (such as interest rates) has been changed by policy. The more general issue is where the knowledge of the agent should stop: whether the agent can compute the impact of its actions, of other's actions in response to his, etc. The issue knits a continuous ith between general equilibrium theory of perfect markets, and the theory of games. The latter has usually been devoid of general statements about market behaviour. A closer link between game theory and the general equilibrium theory of markets would improve this situation.

\section{SUMMARY}

We have emphasised the importance of the analysis of markets in the political economy agenda. This analysis should be a general, qualitative and offer a strong mathematical foundation for the best development and communication of the ideas. Within this agenda, a main open issue is the relationship between markets and democracy. This issue can be developed in a formalised fashion, by using the mathematical foundations offered by the theory of general equilibrium of competitive markets, and by the analysis of democracy offered in social choice theory.

Within the theory of markets, we indicated the desirability of remaining within the general competitive model rather than dealing with ad hoc market imperfections. Despite their immediate appeal, the latter are typically dismissed as ephemeral, and expected to disappear as more markets emerge and the imperfections decrease in importance.

The economic environment of the competitive market was singled out as an area ripe for further research after a decade of fast development of results which attracted wide interest and debate. The Arrow-Debreu model extended to admit endogenous, market responsive endowments was examined in some detail. Examples were produced of the difference in the results of the competitive markets theory which emerge when endowments are endogenous rather than part of the fixed, non-market, environment which appears in the Arrow-Debreu model. We examined the implications of endogenous endowments within the general model of competitive markets, and in international economics. In the latter we mentioned the emphasis on relative advantages as opposed to 'leapfrogging technologies'.

Another area of research which produced widely discussed results involving changes in the market environment is that of transfers in market economies. The area deals with variations in the endowments of the agents which leave the total endowments of the economy unchanged. These variations are voluntary rather than market dependent, but they have an impact on market prices. The results here are of a 'comparative static' nature. We discussed recent results on the transfer paradox, which have wide application to international economic policies at present.

In sum: the competitive market and its environment provides a fruitful area for research. Original results have been obtained which attracted wide attention over a short period. Several important and interesting questions remain open, dealing with issues of practical importance to which economic theory has not provided general theoretical solutions. The suggestion is for political economy to take over the research agenda and to do so by utilising the advanced, elegant and general methods which give the theory of markets its current standing in economics.

The aim is to advance our understanding of markets, their value and their limitations, in a general, qualitative way. A strong, simple logical framework leads naturally to the achievement of results. Once the proper foundations are laid out, one can build. Political economy must build on abstract and general mathematical thinking. It is the only way to assure clarity, a strong foundation, and the desired advance in areas which are of great importance for intellectuals and for those whose lives depend on it.

\section{REFERENCES}

ARRow, K. J. and HAHN, F. (1971). General Competitive Analysis, San Francisco, HoldenDay.

BRown, D. J. and HeAL, G. M. (1979). Equity, efficiency and increasing returns, Review of Economic Studies, Vol. 47 (4), No. 145.

BRown, D. J. and HEAL, G. M. (1983). Marginal vs. average cost pricing in the presence of a public monopoly, American Economic Review, Papers and Proceedings, Vol. 73.

CHICHILNISKY, G. (1980A). Social choice and the topology of spaces of preference, Advances in Mathematics, Vol. 37, No. 2.

CHICHILNisky, G. (1980B). Basic goods, the effects of commodity transfers and the international economic order, fournal of Development Economics, Vol. 7.

CHICHILNISKY, G. (1981). Terms of trade and domestic distribution: export led growth with abundant labour, fournal of Development Economics, Vol. 8.

CHICHILNISKY, G. (1983). The transfer problem with three agents once again: characterisation, uniqueness and stability, fournal of Development Economics, Vol. 12. 
CHICHILNISKY, G. (1986A). A general equilibrium theory of north-south trade, in Equilibrium Analysis, Essays in Honour of Kenneth F. Arrow, Vol. II, edited by W. Heller, R. STARR and O. Starrett, Cambridge, C.U.P.

Chichilnisky, G. (1986B). The topological complexity of manifolds of preferences, in Contributions to Mathematical Economics in Honor of Gerard Debreu, edited by W. HILlDENBRAND and A. MAS-Colell, Amsterdam, North Holland.

Chichinisky, G. (1990A). Development at the turn of the century, Proceedings of the Islamabad Council of World Affairs, Islamabad, Pakistan also, Asian fournal of Social and Economic Studies, 1990.

CHICHILNISKY, G. (1990B). General equilibrium and social choice with increasing returns, Annals of Operations Research, Vol. 23.

CHICHILNISKY, G. and HEAL, G. M. (1982). General equilibrium theory with variable endowments, Mimeo, Columbia University Department of Economics Working Paper Series.

Debreu, G. (1954). Competitive equilibrium and Pareto optimum, Proceedings of the National Academy of Sciences of the U.S.A., Vol. 40.

DeBreu, G. (1976). The application to economics of differential topology and global analysis: regular differentiable economies, The American Economic Review, Papers and Proceedings, Vol. 66, No. 2.

FINDLAY, R. and KIERZKOWSKI, H. (1983). International trade and human capital: a simple general equilibrium model, fournal of Political Economy, Vol. 91, No. 61.

GeANAKoplos, J. and HeAL, G. M. (1983). A geometric interpretation of the transfer paradox with three agents, fournal of Development Economics, Vol. 13.

HeAL, G. M. (1980). Interperiod allocation and intergenerational equity, Erschofbare Resourcen Schiften des vereins fur Socialpolitik, Vol. 108.

JONES, R. W. (19675). The structure of simple general equilibrium models, fournal of Political Economy, Vol. 73.

KEMP, M. C. and JoNES, R. (1972). Variable endowments and the theory of international trade, fournal of Political Economy, Vol. 70, pp. 30-36.

Lysy, F. (1985). Graciela Chichilnisky's model of north-south trade, fournal of Development Economics, Vol. 18.

SEN, A. (1970). Collective Choice and Social Welfare, San Francisco, Holden-Day.

\section{APPENDIX}

The purpose of this appendix is to prove the convexity of the production possibility set of the model presented in Section 2(a). It suffices to prove that $\mathrm{d}^{2} / B / \mathrm{d} I^{2}>0$.

Let $B=f\left(p_{B}\right)$ and $I=g\left(p_{B}\right)$. Then $\mathrm{d} B / \mathrm{d} I=f^{\prime} \mid g^{\prime}$ and

$$
\mathrm{d}^{2} B / \mathrm{d} l^{2}=\left[\left(g^{\prime} f^{\prime \prime}-f^{\prime} g^{\prime \prime}\right) /\left(g^{\prime}\right)^{2}\right]\left(1 / g^{\prime}\right) \text {. }
$$

Computation reveals:

$\left.\mathrm{d} B / \mathrm{d} p_{B}=\left(p_{I} / p_{B}^{2}\right)\left[\left(c_{1} c_{2} a\right) / D^{2}\right]+\left[\left(2 \mathrm{a}_{1}{ }^{2} \mathrm{a}_{2} b\right) / D^{3}\right]\left(p_{I}{ }^{2} / p^{3}{ }_{B}\right)-\left[2 \mathrm{a}_{1} \mathrm{a}_{2}{ }^{2} b\right) / D^{3}\right]\left(p_{I} / p_{B}^{2}\right)=f^{\prime}$.

$d^{2} B / \mathrm{d} p_{B}^{2}=\left[\left(-2 c_{1} c_{2} a\right) / D^{2}\right]\left(p_{I} / p_{B}^{3}\right)-\left[\left(6 \mathrm{a}_{1}{ }^{2} \mathrm{a}_{2} b\right) / \mathrm{D}^{3}\right]\left(p_{I}{ }^{2} / p_{B}{ }^{4}\right)+\left[\left(4 \mathrm{a}_{1} \mathrm{a}_{2}{ }^{2} b\right) / \mathrm{D}^{3}\right]\left(\mathrm{p}_{\mathrm{I}} / \mathrm{p}_{\mathrm{B}} 3\right)=\mathrm{f}^{\prime \prime}$.

$\mathrm{dI} / \mathrm{dp}_{\mathrm{B}}=\left[\left(-2 \mathrm{a}_{1}{ }^{3} b\right) / \mathrm{D}^{3}\right]\left(p_{I}{ }^{2} / p_{B}{ }^{3}\right)+\left[\left(2 \mathrm{a}_{1}{ }^{2} \mathrm{a}_{2} b\right) / \mathrm{D}^{3}\right]\left(p_{I} / p_{B}{ }^{2}\right)-\left(\mathrm{c}_{1}{ }^{2} a \mathrm{p}_{\mathrm{I}}\right) / \mathrm{D}^{2} \mathrm{p}_{\mathrm{B}}{ }^{2}=\mathrm{g}^{\prime}$.

$\left.\mathrm{d}^{2} I / \mathrm{d} p_{B}{ }^{2}=\left[\left(6 \mathrm{a}_{1}^{3} b\right) / D^{3}\right]\left(p_{I}^{2} / p_{B}^{4}\right)-\left[4 \mathrm{a}_{1}^{2} a_{2} \mathrm{~b}\right) / D^{3}\right]\left(p_{I} / p_{B}{ }^{3}\right)+\left(2 \mathrm{c}_{1}^{2} a p_{I}\right) / D^{2} p_{B}{ }^{3}=g^{\prime \prime}$.

From the above one obtains:

$\varepsilon^{\prime} f^{\prime \prime}-f^{\prime} g^{\prime \prime}=-p_{I}^{3} / p_{B}^{6}\left[\left(2 a b a_{1}{ }^{2} c_{1}\right) / D^{4}\right]-p_{I}^{4} / p_{B}^{7}\left[\left(10 a_{1}^{5} a_{2} b^{2}\right) / D^{6}\right]$.

This term is clearly negative so from (21) it follows that

$$
\text { - } \operatorname{Sign}\left(\mathrm{d}^{2} B / \mathrm{d} I^{2}\right)=-\operatorname{sign}\left(g^{\prime}\right) \text {. }
$$

Now, $g^{\prime}=\left(\mathrm{a}_{2}-\mathrm{a}_{1} p_{l} / p_{B}\right)\left(2 p_{I} / p_{B}^{2}\right)\left(a_{1}^{2} b / D^{3}\right)-\left(\mathrm{c}_{1}^{2} a / D^{2}\right)\left(p_{I} / p_{B} 2\right)$

which from (8) is

$$
g^{\prime}=\left(-p_{M} 2 p_{I} \mathrm{a}_{1}^{2} b\right) / p_{B}{ }^{3} D^{2}-\left(\mathrm{c}_{\lambda}{ }^{2} a \mathrm{p}_{1}\right) / D^{2} p_{B}{ }^{2} .
$$

It is therefore clear that $g^{\prime}$ is always negative, the relevant frontier is always convex, and the equilibrium is always inefficient since preferences are linear. It is also apparent that the conditions (19) and (20) used to establish the strict positivity of $B^{\star}$ and $I^{\star}$ are satisfied by sets of the parameter values $\mathrm{a}^{1}, \mathrm{a}_{2}, \mathrm{c}_{1}, \mathrm{c}_{2}, a, b, c$, and $d$ which contain open sets. The essential properties of the example are therefore robust to small changes in the values of the parameters specifying the technology, preference and endowment functions in the model of Section 2(a). Walrasian stability of the equilibrium has been established in Chichilnisky and Heal (1979). 